\title{
Selective Serotonin Reuptake Inhibitors Affect Neurobehavioral Development in the Human Fetus
}

\author{
Eduard JH Mulder*,', Frédérique FT Ververs' ${ }^{2}$, Roel de Heus' and Gerard HA Visser' \\ 'Department of Perinatology and Gynecology, Wilhelmina Children's Hospital, University Medical Centre, Utrecht, The Netherlands; \\ ${ }^{2}$ Department of Clinical Pharmacy, University Medical Centre, Utrecht, The Netherlands
}

\begin{abstract}
The aim of this prospective study was to investigate whether selective serotonin reuptake inhibitors (SSRIs) utilized by pregnant women influence fetal neurobehavioral development. In this observational study we investigated developmental milestones of fetal behavior during the pregnancy of women with psychiatric disorders who took SSRIs throughout gestation (medicated group; $n=96$ ) or who had discontinued medication early in gestation or before conception (unmedicated group; $n=37$ ). Healthy unexposed fetuses of women without mental disorders comprised the control group $(n=130)$. Ultrasonographic observations of fetal behavior were made three times in pregnancy (TI-T3). Effects of SSRIs were studied over a wide range of dosages (low, standard, or high) and for different drug types. Fetuses exposed to standard or high SSRI dosages compared with control, unmedicated, or low-medicated fetuses showed significantly increased motor activity at the beginning $(\mathrm{TI})$ and end of the second trimester (T2). They particularly exhibited disrupted emergence of non-rapid eye movement (non-REM; quiet) sleep during the third trimester, characterized by continual bodily activity and, thus, poor inhibitory motor control during this sleep state near term (T3). The SSRI effects on the fetus were dose related, but independent of SSRI type. The results demonstrate changes in fetal neurobehavioral development associated with standard and high SSRI dosages that are observable throughout gestation. A first-choice SSRI type was not apparent. Bodily activity at high rate during non-REM sleep in SSRI-exposed fetuses is an abnormal phenomenon, but its significance for postnatal development is unclear. Neuropsychopharmacology (20II) 36, 196I-1971; doi:10.1038/npp.201 I.67; published online 27 April 201।
\end{abstract}

Keywords: fetus; pregnancy; antidepressants; SSRI; fetal sleep-wake organization; fetal behavioral states

\section{INTRODUCTION}

Selective serotonin reuptake inhibitors (SSRIs) are increasingly utilized in pregnancy to treat major affective (anxiety, depression) and other psychiatric disorders (Andrade et al, 2008; Vaswani et al, 2003; Ververs et al, 2006). Although SSRIs are currently believed to carry no risk of major fetal malformations (Louik et al, 2007), there are still concerns that relate to increased risks of preterm birth, low birth weight, and pulmonary hypertension (Rahimi et al, 2006; Chambers et al, 2006). In addition, neonatal symptoms ('poor adaptation'), involving altered motor activity (restlessness, jitteriness) and sleep disturbance, are abundant after prenatal exposure to SSRIs (Sanz et al, 2005; Zeskind and Stephens, 2004). It is unknown whether the neonatal problems result from acute cessation of SSRI exposure at birth (withdrawal), or result from alterations in fetal

\footnotetext{
*Correspondence: Dr EJH Mulder, Department of Perinatology and Gynecology, Wilhelmina Children's Hospital, University Medical Centre, KE 04.123.I, Lundlaan 6, 3584 EA Utrecht, The Netherlands, Tel: + 3188755 7547, Fax: + 3188755 5320, E-mail: emulder@ umcutrecht.nl

Received 16 December 2010; revised 24 March 2011; accepted 28 March 2011
}

neurobehavioral development secondary to sustained prenatal exposure (ie, an in utero effect; Lattimore et al, 2005).

SSRIs taken by the mother might directly affect the fetus. They readily cross the placenta and enter the fetal brain where serotonin and its neurons and receptors are present from early in life onward (Kinney et al, 2007). The inability of the fetus to metabolize SSRIs and the second pass of SSRIs through reuptake from the amniotic fluid may render the fetus also indirectly but continually exposed to raised drug levels. In sheep, maternal infusion of fluoxetine for 8 days has been shown to alter fetal rapid eye movement (REM) sleep and electrical brain activity (Morrison et al, 2005). In rodents, long-term neurobehavioral effects have been described in offspring after perinatal exposure to SSRIs (Maciag et al, 2006; Noorlander et al, 2008).

In normal human pregnancy, fetal generalized body movements occur randomly during the first half of gestation. They become progressively clustered to appear as phases of rest and activity around 28 weeks of gestation, which are fairly associated with patterns of low and high heart rate variability, respectively. As the fetuses grow older, episodes of rest and activity and their heart rate patterns become increasingly linked to absence and presence of eye movements, respectively. Eventually, stable non-REM 
(quiet) and REM (active) sleep states with sharp transitions are present near term (Nijhuis et al, 1982; Visser et al, 1992). Fetal sleep regulation is a well-controlled behavior reflecting the primary brain activity at this stage of development.

Previous ultrasound studies of fetal behavior have proven to be a powerful means of detecting variations in antenatal CNS functioning under normal and abnormal conditions (Mulder et al, 1987, 1998, 2009; Nijhuis et al, 1999). However, no data have been collected regarding the possible effect of SSRI exposure on neurobehavioral development in the human fetus.

The aim of this study was to compare behavioral development in a group of fetuses exposed to SSRIs throughout pregnancy with a control group of healthy unexposed fetuses. To separate potential effects of SSRIs on fetal behavior from those of depression and other mental disorders per se, we included a third group of fetuses of women who suffered from psychiatric problems but were unmedicated. In this prospective observational study, fetal motor behavior, heart rate, and the emergence of behavioral (sleep-wake) states were examined with special emphasis on SSRI type and dosage.

\section{MATERIALS AND METHODS}

\section{Participants}

This study was part of a larger prospective project on the impact of SSRI antidepressant medication use during pregnancy. Potentially eligible participants were identified by physicians or midwives at participating sites and were approached by the study coordinator (FFTV). Exclusion criteria were fetal abnormality, multiple pregnancy, preexistent maternal disease, psychosis or bipolar disorder, and use of benzodiazepines or medications classified as category $\mathrm{D}$ or $\mathrm{X}$ according to the FDA guidelines (Lo and Friedman, 2002). The study population comprised a total of 262 pregnant women with mood disorders and other psychiatric illnesses. Of these, 133 (51\%) women agreed to participate in the present study involving additional ultrasound sessions for the study of fetal behavior in our research unit. Maternal and neonatal demographic differences between those who participated and those who declined were not statistically significant. The 133 women were recruited from the antenatal clinic at Utrecht Medical Centre (tertiary hospital) or were self-referrals or physician referrals for research purpose only from first- and secondline obstetric practices in the surrounding area. All participants (continuers and discontinuers, see below) had been taking SSRI therapy for at least 6 months. Psychiatric diagnosis, SSRI assignment, dose management, and drug discontinuation were at the discretion of the treating physician. Clinical diagnoses comprised major depression $(n=51)$, panic disorder $(n=12)$, a combination of both $(n=62)$, generalized anxiety disorder $(n=4)$, obsessivecompulsive disorder $(n=2)$, and bulimia $(n=2)$.

All pregnancies were dated by the last menstrual period and an ultrasound scan before 12 weeks of gestational age (wGA). The study was approved by the Dutch Central Committee on Research Involving Human Subjects (CCMO) and the local ethics committee. Subjects were enrolled on a voluntary basis after written informed consent had been obtained.

At study entry (15-19 wGA), 96 women (72\%) were receiving SSRIs. They had conceived during treatment and remained on medication throughout pregnancy with no change of drug type (medicated study group). In addition, $37(28 \%)$ women were not receiving SSRI therapy at study entry and did not resume taking SSRIs during the remainder of their pregnancy. They had discontinued medication before conception or before 12 wGA (unmedicated study group). The comparison group comprised 130 healthy women with no history of psychiatric or other illnesses. These were unexposed pregnancies that remained uncomplicated throughout the entire gestation. All fetuses of the comparison group were born healthy at full term $(\geqslant 37 \mathrm{wGA})$ and of appropriate weight for gestation.

\section{Methods}

A longitudinal design with three times of assessment aimed to collect data for the mother and her fetus at 15-19 wGA at time 1 (T1), 27-29 wGA at time 2 (T2), and 37-39 wGA at time 3 (T3). A questionnaire booklet was mailed to the participant $\sim 1$ week before each appointment. Upon completion, they were returned directly to the study coordinator. The principal investigator (EJHM) remained blind to the mental health and drug status of the women until all fetal data had been collected and analyzed.

\section{Maternal Data Collection}

Data were collected on sociodemographic status, lifestyle, and medical and obstetric history. The information gathered related to maternal age, socioeconomic status (SES; highest achieved educational level), marital status, parity, psychiatric diagnosis, duration of therapy, time at discontinuation as appropriate, type and dosage of SSRI, cigarette smoking, and alcohol consumption.

The defined daily dose (DDD) of SSRIs used in this study was $20 \mathrm{mg}$ for paroxetine, fluoxetine, and citalopram; $50 \mathrm{mg}$ for sertraline; and $100 \mathrm{mg}$ for fluvoxamine and venlafaxine, according to the ATC-DDD index (WHO, 2008). These values were set to 1 to indicate standard exposure. For each woman, the prescribed total daily dose was expressed as a multiple of the standard, the mDDD. For example, mDDD was 3 for a woman who was daily using $60 \mathrm{mg}$ of paroxetine. Participants were categorized as having low intake $(0<$ $\operatorname{mDDD}<1)$, standard intake $(\mathrm{mDDD}=1)$, or high intake $(\mathrm{mDDD}>1)$. Absolute $\mathrm{mDDD}$ values were also used to compare drug effects across the different SSRI types.

The following self-administered questionnaires were applied. Anxiety was assessed with the State-Trait Anxiety Inventory (STAI) (Spielberger et al, 1970). The STAI comprises two scales, each containing 20 items to be rated on a four-point scale (range of possible scores 20-80). This standardized questionnaire differentiates between state anxiety (how respondents currently feel) and trait anxiety that reflects anxiety proneness (how respondents generally feel). The state anxiety scale was completed in $10 \mathrm{~min}$ before ultrasound recording. Pregnancy-specific fears and worries were rated using a 10-item version of the Pregnancy-Related Anxieties Questionnaire (PRAQ). This instrument deals 
with the components, 'fear of child integrity', 'fear of giving birth', and 'concern about bodily appearance', in a fivepoint response format; range of possible scores 0-40 (Huizink et al, 2004). Depression was measured using the Edinburgh Depression Scale (EDS), a 10-item scale that has satisfactory sensitivity and specificity for assessing prepartum depression; range of possible scores 0-30 (Cox et al, 1996).

One maternal saliva sample was collected halfway the fetal ultrasound session on each occasion and stored at $-70{ }^{\circ} \mathrm{C}$ until assay. Cortisol content was determined according to standard procedure (Huizink et al, 2002).

\section{Fetal Data Collection and Analysis}

Fetal recordings were made following established procedures with the women semi-recumbent, slightly tilted to the left, in a quiet environment (Mulder et al, 1987). Real-time ultrasound observations of fetal generalized body movements (GMs) were made for $1 \mathrm{~h}(\mathrm{~T} 1, \mathrm{~T} 2)$ or $2 \mathrm{~h}(\mathrm{~T} 3)$ between 1000 and $1600 \mathrm{~h}$, starting at least $1.5 \mathrm{~h}$ after the last meal. The images were stored for off-line analysis; the presence of GM was marked during full image replay. The number and duration (in seconds) of GM bursts were subsequently determined for each recording (ten Hof et al, 1999). Fetal heart rate (FHR) was monitored with a cardiotocograph using Doppler ultrasound (Hewlett Packard, Böblingen, Germany). Continuous FHR monitoring occurred simultaneously with fetal visualization at T2 and T3, but is technically not possible at T1. Off-line, all FHR tracings were judged visually and divided into episodes of heart rate pattern (HRP) A through D (see below). Fetal REMs were observed and marked online at T3 by a second investigator using another ultrasound device.

\section{Macroanalysis}

Behavioral (sleep-wake) states are present in healthy fetuses after 36 wGA (Visser et al, 1992). Figure 1 shows an example of normal state organization in a near-term fetus. States are characterized by stable concordant association of the parameters of three variables (HRP, GM, and EM) for long periods of time and the simultaneous change of parameters at transitions $(<3 \mathrm{~min})$. The 3 -min moving window technique, a smoothing procedure, was used to draw up profiles for each T3 recording, indicating the on and off time of GM and EM combined with the presence of a particular HRP rounded off to the nearest $0.5 \mathrm{~min}$ (Mulder et al, 1987; Nijhuis et al, 1982). The temporal association between parameters of the state variables was assessed by two complementary procedures. First, the presence of each of four distinct behavioral states was identified based on all three variables (Mulder et al, 1987; Nijhuis et al, 1982). Episodes of state 1F (S1F; quiet, non-REM sleep) are defined by the absence of both general and eye movements and a stable heart rate with a small oscillation bandwidth (HRPA); FHR accelerations may incidentally occur but must be disregarded when evaluating this pattern (Mulder et al, 1987). State 2F (S2F; active, REM sleep): general and eye movements are present and heart rate has a wide oscillation bandwidth between the frequent accelerations (HRPB). State 3F (S3F; quiet awake): general movements are absent and eye movements present; heart rate is stable without accelerations (HRPC). State 4F (S4F; active awake): frequent vigorous general movements in the presence of eye movements; unstable heart rate with large and prolonged accelerations (HRPD). No-state identified (NoS) was considered if none of the S1F-S4F combinations was valid. The presence of S1F-S4F and NoS was expressed as the percentage of recording time. Behavioral state organization

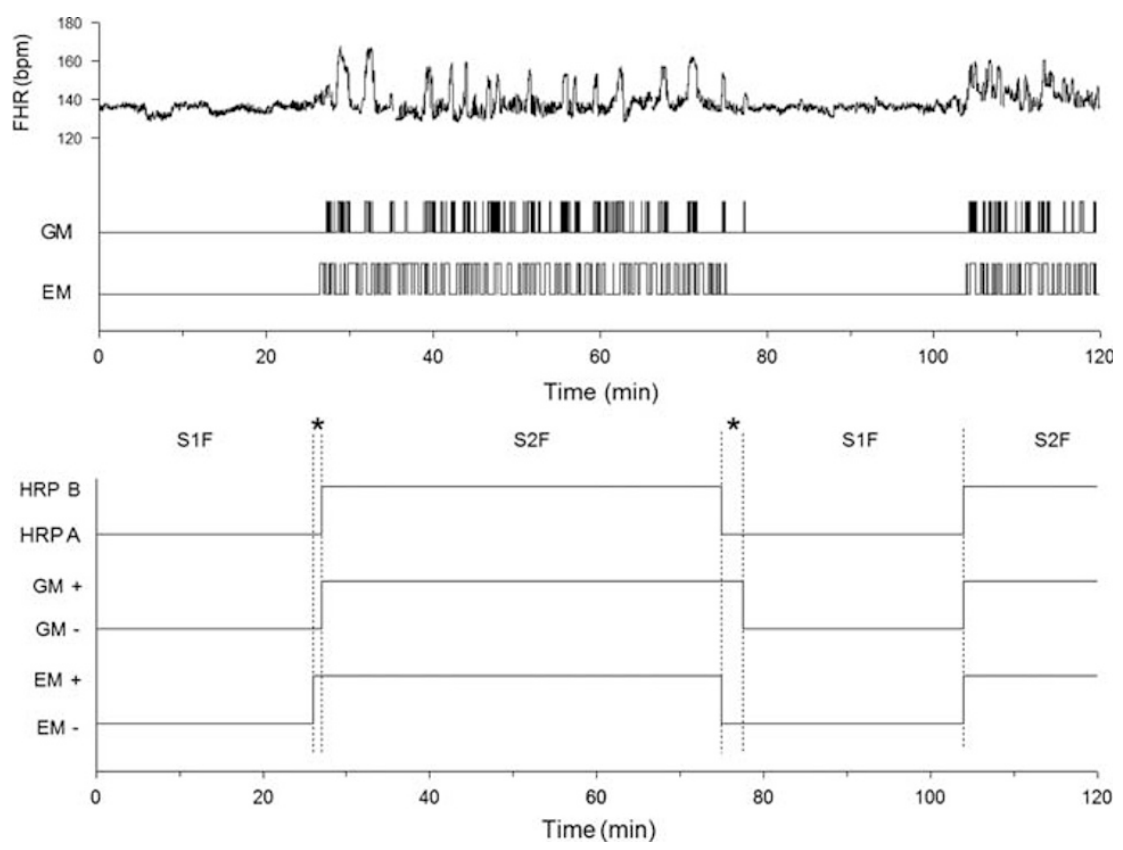

Figure I The $2 \mathrm{~h}$ fetal behavioral state recording made at 38 weeks of gestation from an unmedicated woman with psychiatric problems. Fetal state organization is normal and comparable with that seen in healthy unexposed fetuses in the comparison group. Presented are the original data for fetal heart rate (FHR), general movements (GMs), and rapid eye movements (REMs; upper panel); and the smoothed state profile indicating episodes of FHR pattern (HRPs A and B), and the presence (+) and absence (-) of GMs and EMs (lower panel). SIF, state IF; S2F, state 2F; *no-state identified. 
reflects the degree of neurophysiologic integrity and maturity, with \%NoS being an overall measure of disorganization (Visser et al, 1992). However, when increased, the $\%$ NoS does not tell which parameter(s) specifically underlie(s) state dissociation. Therefore, based on our results, the association between pairs of state parameters was also analyzed (Nijhuis et al, 1999). For each recording, we calculated the time that one of the three variables was absent $(-)$ or present $(+)$ during the time that another variable was absent or present. With HRPA denoted as $(-)$ and HRPB as $(+), 12$ possible combinations were obtained $(\mathrm{EM} \pm v s \mathrm{HRP} \pm$; $\mathrm{EM} \pm v s \mathrm{GM} \pm$; and $\mathrm{GM} \pm v s \mathrm{HRP} \pm)$. The degree of association between pairs was expressed as percent linkage.

\section{Microanalysis}

For episodes of HRPA and HRPB lasting $\geqslant 10$ min identified at T2 and T3, computerized numerical FHR analysis yielded information about basal FHR (in b.p.m.) and long-term FHR variability (in $\mathrm{ms}$ ) as described previously (Nijhuis et al, 1998a, 1998b). The sum duration of GM bursts (in seconds) was expressed as percentage of time (incidence) and calculated for total recording (T1) and for episodes of HRPA and HRPB lasting $\geqslant 10 \mathrm{~min}$ (T2, T3) (ten Hof et al, 2002). Note that GMs were treated differently between macro- and micro-analyses. With the former, GM was considered continuously present if bursts occurred at $<3$ min apart, whereas with the latter method, GMs were considered for the time they had been actually observed.

\section{Statistics}

SPSS for Windows (version 16; SPSS, Chicago, IL) was used for data management and statistical analysis. Results were summarized with the use of standard descriptive statistics: counts and percentages for categorical variables, and means and SD or SE for continuous variables. Main study groups were evaluated for equivalence in patient characteristics using the $\chi^{2}$ or Fisher's exact test for categorical measures and one-way ANOVA for continuous variables. Analyses of the fetal outcome measures were performed in two steps using multivariable analysis of variance (GLM) with Sidak post hoc comparisons. First, possible differences in fetal behavior between the three main groups were evaluated. Second, we studied differences in fetal behavior between the unmedicated group and the medicated subgroups (low, standard, and high $\mathrm{mDDD}$ ) and also examined linear relationships between fetal variables and the absolute mDDD values by regression analysis (GLM). With all tests, significance was assumed at the level of $\alpha=0.05$ (two sided).

\section{RESULTS}

\section{Descriptive Statistics and Preliminary Analyses}

At study entry (T1), the unmedicated and medicated groups did not differ with regard to psychiatric diagnoses $\left(\chi^{2}=0.82, P=0.84\right)$, history of admission to a psychiatric clinic $\left(\chi^{2}=1.70, P=0.19\right)$, and SSRI dosage before T1 (median $\mathrm{mDDD}$ was 1 ; range $0.2-3.0 \mathrm{mDDD}$ for both groups; $P=0.44)$.

Women in the medicated group compared with control women were older, more often multiparous, and had shorter gestation and infants with lower Apgar scores (Table 1). There were no significant differences in the use of alcohol or tobacco, (adjusted) birth weight, mode of delivery, SES, or marital status across the main groups (Table 1 or data not shown).

Table I Characteristics of Participants in the Comparison Group, Unmedicated Study Group, and Total Medicated Study Group

\begin{tabular}{|c|c|c|c|c|}
\hline & \multirow{2}{*}{$\begin{array}{l}\text { Comparison group } \\
\qquad(n=130)\end{array}$} & \multicolumn{2}{|c|}{ Study group } & \multirow{2}{*}{$\begin{array}{c}\text { ANOVA } \chi^{2} ; \\
\text { P-value }^{\mathrm{a}}\end{array}$} \\
\hline & & Unmedicated $(n=37)$ & Total medicated $(n=96)$ & \\
\hline Maternal age (years) & $30.8(5.1)$ & $31.4(4.5)$ & $32.5(4.8)^{b}$ & $F(2,260)=3.22 ; P<0.05$ \\
\hline Nulliparity (n; \%) & $123(94.6 \%)$ & $19(51.4 \%)^{c}$ & $47(49.0 \%)^{b}$ & $\chi^{2}=69.03 ; P<0.0001$ \\
\hline Smoking ( $n ; \%)$ & $23(17.7 \%)$ & $8(21.6 \%)$ & $17(17.7 \%)$ & $\chi^{2}=0.33 ; P=0.85$ \\
\hline Gestation at delivery (weeks) & $40.0(1.1)$ & $39.4(1.9)$ & $39.1(2.1)^{b}$ & $F(2,260)=7.19 ; P<0.001$ \\
\hline Delivery at $<37$ weeks & $0(0 \%)$ & $2(5.4 \%)$ & $8(8.3 \%)^{b}$ & $\chi^{2}=10.87 ; P<0.005$ \\
\hline Cesarean section ( $n$; \%) & $10(7.7 \%)$ & $4(10.8 \%)$ & $15(15.6 \%)$ & $\chi^{2}=3.54 ; P=0.17$ \\
\hline Birth weight (g) & $3463(444)$ & $3392(561)$ & $3395(584)$ & $F(2,260)=0.57 ; P=0.57$ \\
\hline
\end{tabular}

${ }^{a}$ One-way ANOVA or $\chi^{2}$ testing for significant differences across the three main groups.

b Total medicated group vs comparison group; $0.0001<P<0.05$.

'Unmedicated group vs comparison group; $P<0.0001$.

${ }^{\mathrm{d} B i r t h}$ weight was expressed as Z-score according to the Dutch growth charts adjusted for parity, sex, and gestational age (Visser et al, 2009)

eTotal medicated group vs unmedicated group; $0.01<P<0.02$.

Data are presented as mean (SD) or number (\%). 
Of the 133 women in the study groups, 28 women attended once, 45 twice, and 60 completed all three sessions. For the comparison group $(n=130)$, these numbers were 2, 16 , and 112, respectively. Several factors account for the difference in participation rate. Study group participants compared with control subjects were allowed to enter the study at any stage of pregnancy and they were more likely to drop out because of loss of interest, physical or mental discomfort, or delivery before the last session. The numbers of participants (recordings) at $\mathrm{T} 1-\mathrm{T} 3$ were distributed as shown in Table 2. For fetal recordings, there were modest differences in gestational age and time of day at recording (ie, before or after $1200 \mathrm{~h}$ ). Hours of fetal observation obtained from the study and comparison groups were 482 and 393, respectively.

\section{Maternal Drug Use, Psychological Measures, and Cortisol Content}

All medicated women were on SSRI monotherapy. The majority of these (44\%) used paroxetine (type 1), $21 \%$ used fluoxetine (type 2), 20\% used citalopram (type 3), 7\% used venlafaxine, $4 \%$ used fluvoxamine, and $4 \%$ took sertraline (the latter three combined; type 4). The median mDDD was 1 (range $0.2-3.0 \mathrm{mDDD}$ ) on each occasion.

The women in the unmedicated and medicated groups had similar scores on the STAI, PRAQ, and EDS questionnaires. Both study groups had higher stress/anxiety and depression scores compared with control women (Table 2). Maternal cortisol content did not differ across the main groups at $\mathrm{T} 1$ and $\mathrm{T} 2$, but was higher in the unmedicated and

Table 2 Characteristics of Fetal Ultrasound Sessions and Maternal Psychological Measures in the Comparison Group, Unmedicated Study Group, and Total Medicated Study Group

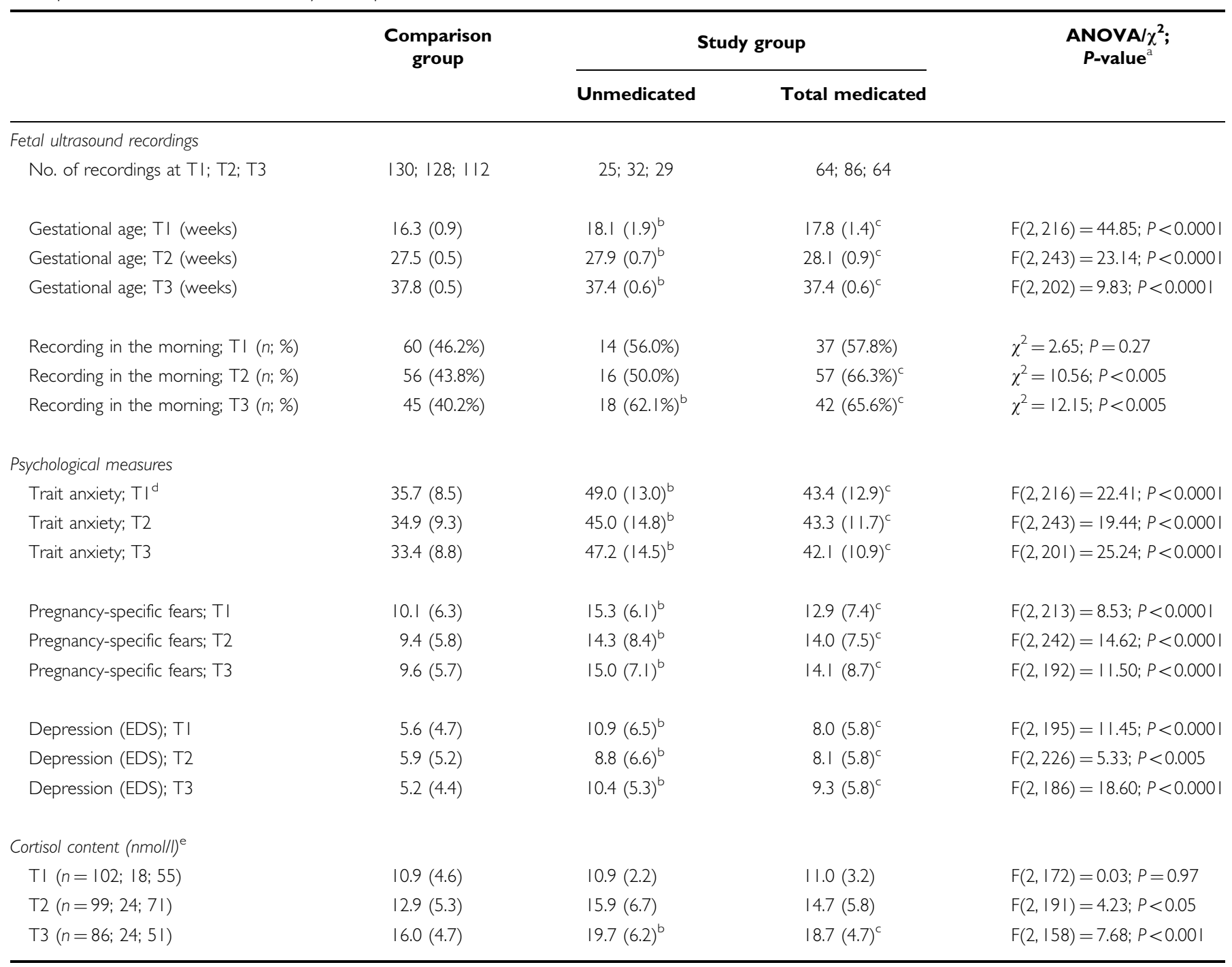

${ }^{a}$ One-way ANOVA or $\chi^{2}$ testing for significant differences across the three main groups.

bUnmedicated group vs comparison group; $0.0001<P<0.05$.

${ }^{c}$ Total medicated group vs comparison group; $0.0001<P<0.02$.

${ }^{d}$ Scores on state anxiety not presented because of similarity with those on trait anxiety.

${ }^{\mathrm{e}}$ Assessment in subgroups.

TI: I5-19 weeks of gestation; T2: 27-29 weeks of gestation; T3: 37-39 weeks of gestation.

Data are presented as mean (SD) or number (\%). 
Table 3 Fetal Heart Rate Patterns (HRPs) and Behavioral States (Macroanalysis; Incidences in Italics), and Incidences of General Movements and Numerical Heart Rate Parameters (Microanalysis) for the Comparison Group and the Unmedicated and Total Medicated Study Groups

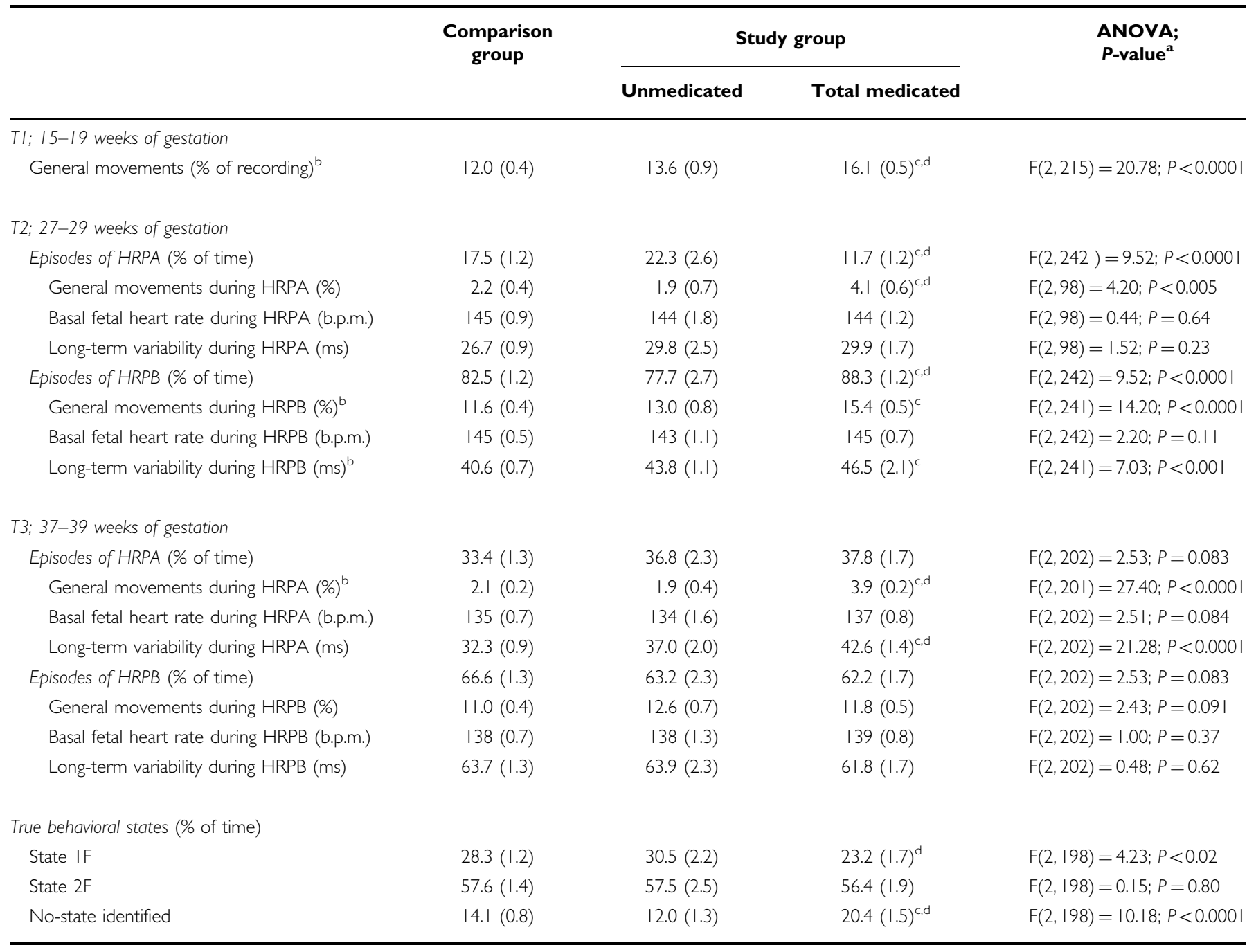

aultivariable ANOVA testing for significant differences across the three main groups.

${ }^{\text {b} A d j u s t e d ~ f o r ~ g e s t a t i o n ~ a t ~ r e c o r d i n g . ~}$

${ }^{c}$ Total medicated group vs comparison group; $0.0001<P<0.05$.

${ }^{\mathrm{d}}$ Total medicated group vs unmedicated group; $0.0001<P<0.05$.

Data are presented as mean (SE) adjusted for gestation at recording where appropriate.

Definitions of fetal behavioral states: state IF (quiet, non-REM sleep): absence of both general and eye movements, and heart rate pattern A (HRPA); state 2F (active, REM sleep): general and eye movements present, and HRPB.

medicated groups at T3 compared with control women (Table 2).

\section{Confounders}

The clinical and psychological factors presented in Tables 1 and 2 were examined as potential confounders. Gestational age and time of the day at recording, state/trait anxiety, pregnancy-specific fears, and depression were modestly associated with some fetal movement and heart rate parameters, notably at T3, in bivariate analyses (Pearson's $r$ between 0.144 and $0.257 ; 0.0001<P<0.05)$. Gestational age at $\mathrm{T} 1$ and $\mathrm{T} 3$ continued to demonstrate a significant association on occasions in multivariable analyses (see
Tables 3 and 4). Maternal age, parity, SES, smoking, alcohol use, cortisol, and fetal sex were unrelated to any of the fetal outcome measures at T1-T3.

\section{SSRIs and the Distribution of FHR Patterns and Behavioral States (Macroanalysis)}

Time 2 (27-29wGA). One or more episodes of HRPB were present during each recording made at T2. However, recordings with episodes of HRPA were less frequently seen in the medicated group (69\%) when compared with the unmedicated (94\%) and comparison (96\%) groups $\left(\chi^{2}=25.52, P<0.0001\right)$. Episodes of HRPs $C$ and D were excluded from analysis because of their low occurrence. 
Table 4 Fetal Heart Rate Patterns (HRPs) and Behavioral States (Macroanalysis; Incidences in Italics), and Incidences of General Movements and Numerical Heart Rate Parameters (Microanalysis) for the Unmedicated Group and the Medicated Subgroups of Low $(0<m D D D<1)$, Standard $(m D D D=1)$, and High $(m D D D>1)$ SSRI Exposure

\begin{tabular}{|c|c|c|c|c|c|c|}
\hline & \multirow{2}{*}{$\begin{array}{l}\text { Unmedicated } \\
\text { group }\end{array}$} & \multicolumn{3}{|c|}{ Medicated group ${ }^{a}$} & \multirow{2}{*}{$\begin{array}{l}\text { ANOVA; } \\
\text { P-value }^{\text {b }}\end{array}$} & \multirow{2}{*}{$\begin{array}{c}\text { Dosage (mDDD); } \\
\beta(\mathrm{SE}) ; P \text {-value }\end{array}$} \\
\hline & & $\begin{array}{l}\text { Low } \\
\text { exposure }\end{array}$ & $\begin{array}{l}\text { Standard } \\
\text { exposure }\end{array}$ & $\begin{array}{c}\text { High } \\
\text { exposure }\end{array}$ & & \\
\hline \multicolumn{7}{|l|}{ TI; 15-19 weeks of gestation } \\
\hline General movements (\% of recording) ${ }^{c}$ & | $3.6(0.9)$ & $15.3(1.2)$ & $17.3(0.8)^{d}$ & $16.2(0.9)^{\mathrm{e}}$ & $F(3,82)=3.21 ; P<0.05$ & $1.47(0.63) ; P<0.05$ \\
\hline \multicolumn{7}{|l|}{ T2; 27-29 weeks of gestation } \\
\hline Episodes of HRPA (\% of time) & $22.3(2.6)$ & $12.8(2.4)^{f}$ & $10.9(1.7)^{d}$ & $11.9(2.2)^{\mathrm{e}}$ & $F(3,|| 3)=5.76 ; P<0.001$ & $-5.13(1.60) ; P<0.005$ \\
\hline General movements during HRPA (\%) & $1.9(0.7)$ & $3.5(1.1)$ & $4.1(0.9)^{d}$ & $5.0(0.9)^{\mathrm{e}}$ & $F(3,40)=2.98 ; P<0.05$ & $1.64(0.58) ; P<0.01$ \\
\hline Episodes of HRPB (\% of time) & $77.7(2.7)$ & $87.2(2.4)^{f}$ & $89.1(2.3)^{d}$ & $88.1(2.5)^{\mathrm{e}}$ & $F(3,|| 3)=5.76 ; P<0.00 \mid$ & $5.13(1.60) ; P<0.005$ \\
\hline General movements during HRPB (\%) & | $3.0(0.8)$ & $14.7(1.0)$ & $15.0(0.9)$ & $16.9(1.1)^{\mathrm{e}}$ & $F(3, \mid 13)=2.75 ; P<0.05$ & $1.43(0.68) ; P<0.05$ \\
\hline Long-term variability during HRPB (ms) & $43.8(1.1)$ & $43.9(1.5)$ & $46.2(1.5)$ & $48.3(2.2)$ & $F(3,|| 3)=3.61 ; P<0.02$ & 3.69 (1.29); $P<0.01$ \\
\hline Long-term variability during HRPA (ms) & $37.0(2.0)$ & $40.5(2.7)$ & $40.7(2.1)$ & $47.5(1.9)^{\mathrm{e}}$ & $F(3,89)=3.48 ; P<0.01$ & $4.82(1.56) ; P<0.005$ \\
\hline Episodes of HRPB (\% of time) & $63.2(2.3)$ & $59.7(2.9)$ & $63.4(3.0)$ & $63.3(2.6)$ & $F(3,89)=0.39 ; P=0.76$ & $-0.63(2.0) ; \mathrm{NS}$ \\
\hline General movements during HRPB (\%) & $12.6(0.7)$ & $12.6(1.0)$ & I $1.2(0.6)$ & । $1.8(0.8)$ & $F(3,89)=0.90 ; P=0.45$ & $-0.73(0.56) ; \mathrm{NS}$ \\
\hline Long-term variability during HRPB (ms) & $63.9(2.3)$ & $63.5(3.7)$ & $61.1(2.8)$ & $61.0(2.0)$ & $F(3,89)=0.33 ; P=0.81$ & -1.31 (1.98); NS \\
\hline \multicolumn{7}{|l|}{ True behavioral states (\% of time) } \\
\hline State IF & $30.5(2.2)$ & $28.8(2.8)$ & $21.9(2.4)$ & $15.2(2.9)^{\mathrm{e}}$ & $F(3,87)=6.38 ; P<0.001$ & $-6.88(1.89) ; P<0.000 \mid$ \\
\hline State $2 \mathrm{~F}$ & $57.5(2.5)$ & $48.5(3.2)$ & $55.1(2.8)$ & $53.7(3.3)$ & $F(3,87)=1.37 ; P=0.26$ & -0.41 (2.18); NS \\
\hline No-state identified & $12.0(1.3)$ & $15.9(2.3)$ & $19.6(2.0)^{d}$ & $25.2(2.4)^{\mathrm{e}}$ & $F(3,87)=7.11 ; P<0.0001$ & $5.90(1.58) ; P<0.000$ I \\
\hline
\end{tabular}

Abbreviation: NS, non significant.

aThe number of fetuses in the low-, standard-, and high-exposure subgroups were 14, 29, and 21 at TI, respectively; 22, 35, and 29 at T2, respectively; and 20, 25, and 19 at $T 3$, respectively.

bMultivariable ANOVA testing for significant differences across the four (sub)groups.

${ }^{\mathrm{C}}$ Adjusted for gestation at recording.

${ }^{d}$ Standard-exposure subgroup vs unmedicated group; $0.002<P<0.05$.

eHigh-exposure subgroup vs unmedicated group; $0.0001<P<0.05$.

fLow-exposure subgroup vs unmedicated group; $P<0.05$.

Data are presented as mean (SE) adjusted for gestation at recording where appropriate. Relationships between absolute mDDD values (dosage) and fetal behavioral parameters were assessed by multivariable linear regression and presented as $\beta$ (SE).

Fetuses in the total medicated group spent less time in episodes of HRPA and more time in HRPB than did fetuses in the comparison and unmedicated groups (Table 3). Compared with the unmedicated group, the effect of SSRIs on the distribution of HRPs was largest for the standardand high-exposure subgroups and was dose dependent (Table 4), with no significant effect of drug type (types 1-4) or other covariates.

Time 3 (37-39wGA). Episodes (at least one) of HRPs A and $\mathrm{B}$ were present among all recordings made at $\mathrm{T} 3$. The proportions of recordings with the presence of HRPC or HRPD as well as their percent incidences were similar across the main groups. Therefore, episodes of HRPs C and $\mathrm{D}$ were not considered further. The percent incidences of HRPs A and B showed similar distributions across the main groups (Table 3) and medicated subgroups (Table 4). However, analysis of the temporal association between the parameters of the three state variables (HRP, GM, and EM) demonstrated altered fetal state distribution across the main groups (Table 3). Fetuses in the total medicated group compared with the control and unmedicated groups showed less \%S1F, increased no-state identified (\%NoS), and unaffected \%S2F (Table 3). Although not different between the unmedicated group and low-exposure subgroup, the $\%$ NoS was increased in the standard- and high-exposure subgroups at the cost of $\% \mathrm{~S} 1 \mathrm{~F}$ (Table 4). The effect of SSRIs on the \%NoS occurred in a dose-dependent manner, but was not related to drug type or other covariates. Examples of normal well-organized fetal behavioral states and of disrupted state organization are shown in Figures 1 and 2, respectively.

The reason for the SSRI-related increase in \%NoS was revealed by $2 \times 2$ analysis of the linkage between state $1 \mathrm{~F}$ parameters, that is, episodes of HRPA, episodes of GM absent (GM-), and episodes of EM absent (EM-). All 


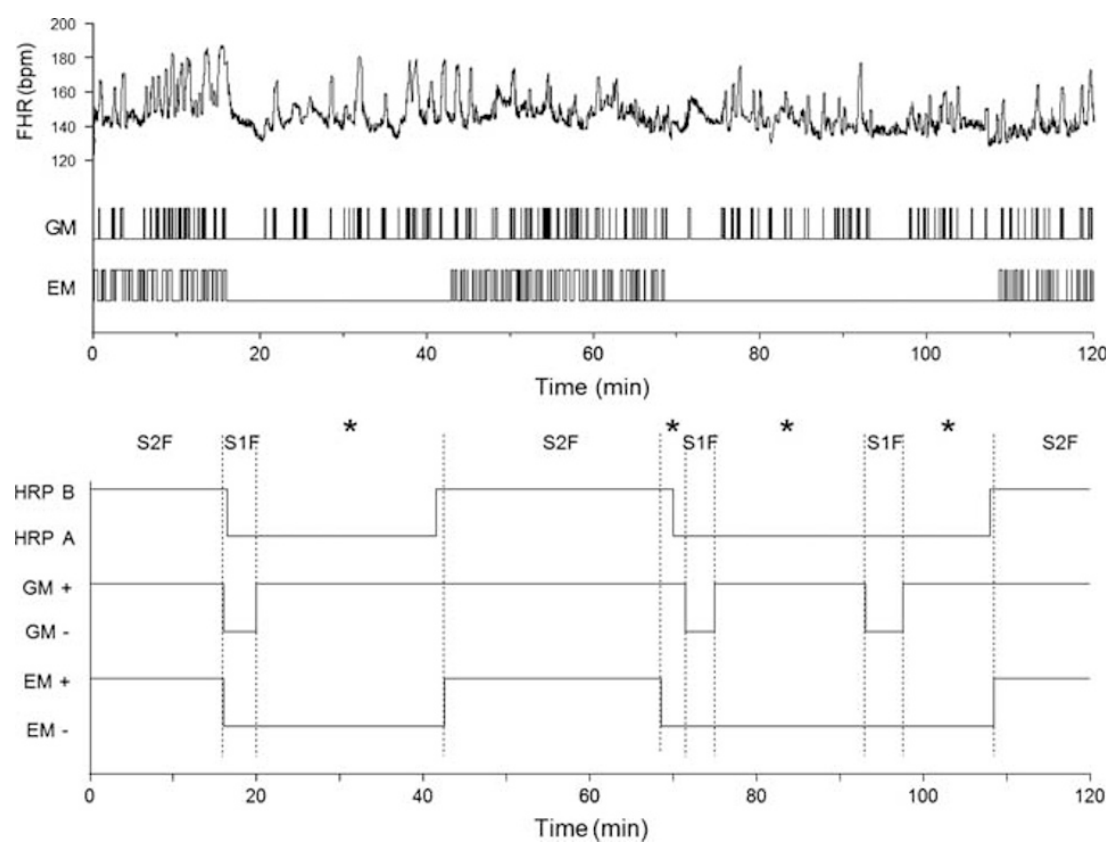

Figure 2 The $2 \mathrm{~h}$ fetal behavioral state recording made at 38 weeks of gestation from a woman with psychiatric problems and long-term use of a highdose SSRI. Presented are the original data for fetal heart rate (FHR), general movements (GMs), and rapid eye movements (REMs; upper panel); and the smoothed state profile indicating episodes of fetal heart rate pattern (HRPs A and B), and the presence $(+)$ and absence $(-)$ of GMs and EMs (lower panel). Note disruption of the two IF combinations (HRPA and absence of EM) through continual presence of GM bursts. SIF: state IF; S2F: state 2F; *no-state identified.

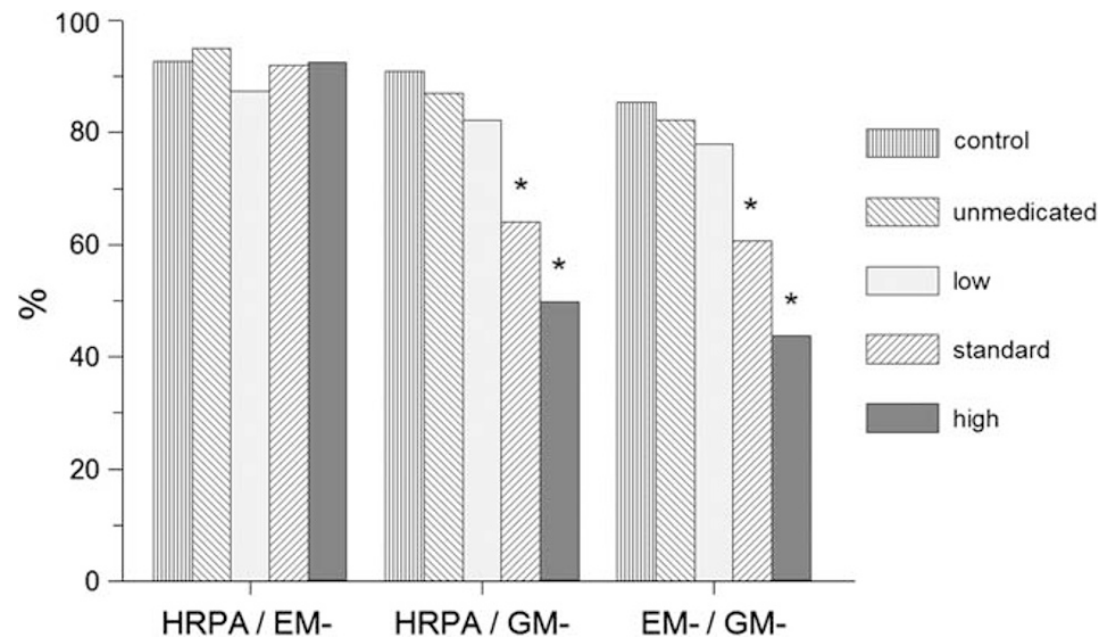

Figure 3 Linkage (\% of time) of pairs of behavioral state IF parameters in the near-term fetus: heart rate pattern A (HRPA); general movements absent (GM-); and eye movements absent (EM-). Linkage data are presented for the comparison (control) and unmedicated groups, and for the three medicated subgroups with low, standard, and high SSRI exposure. There were no significant differences between the comparison and unmedicated groups. $* P<0.001$; SSRI-exposed subgroup vs unmedicated group.

fetuses, irrespective of (sub)group, showed excellent linkage of HRPA and EM-, indicating that EMs were generally absent when the heart rate of the fetus showed an A-pattern (Figure 3). Control fetuses and fetuses of the unmedicated group and low-exposure subgroup also showed excellent linkage of HRPA and GM- and that of EM- and GM-. However, in fetuses exposed to standard or high SSRI doses, the linkage of HRPA/GM- and the linkage of EM-/GMwere highly disturbed. This demonstrates that poor linkage in these fetuses was solely because of GM bursts that continued to be present for an average of $40-60 \%$ of time during the presumed $1 \mathrm{~F}$ state (Figures 2 and 3 ). For $2 \mathrm{~F}$ combinations, linkage of the state parameters was unremarkable (not shown).

\section{SSRIs, Fetal General Movements, and Numerical Heart Rate Parameters (Microanalysis)}

The time fetuses spent making GMs was similar in the comparison and unmedicated groups on each occasion, but 
was increased in the total medicated group (Table 3). Analysis of the medicated subgroups showed no differences in \%GM between the low-exposure subgroup and unmedicated group (Table 4). However, the \%GM was increased in the subgroups with standard and high exposure. These fetuses were more active at $\mathrm{T} 1$, during episodes of HRPB at T2 (but not T3), and notably during episodes of HRPA both at T2 and T3. The observed increases in \%GM at T2 and T3 were generally associated with increases in FHR variability (Tables 3 and 4). Basal FHR did not differ across the main groups (Table 3 ) or medicated subgroups (not shown in Table 4). There were significant linear relationships between the absolute mDDD values and \%GM or FHR variability (Table 4 ). Drug type was not significantly associated with \%GM or FHR variability on any occasion.

\section{DISCUSSION}

The present findings demonstrate that neurobehavioral development in fetuses of low-medicated and unmedicated women with psychiatric problems is indistinguishable from development in healthy control fetuses. However, fetuses exposed to standard or supra-standard SSRI doses developed differently irrespective of SSRI type. Characteristics were increased motor activity at the beginning (T1) and end of the second trimester (T2), and most strikingly lack of inhibitory control of motor output at times the fetuses are supposed to be 'at rest' (T2) or in 'quiet' or non-REM sleep (T3). Thus, fetal effects of standard to high SSRI doses were observable throughout pregnancy, but effects were most prominent on the architecture of non-REM sleep near term.

We observed increased bodily activity in SSRI-exposed fetuses already at 16-19 weeks (T1). These fetuses also spent more time in the activity phase at 27-29 weeks (T2) and showed more general movements during episodes of both HRPA and HRPB. At term (T3), SSRI-exposed fetuses showed good association between episodes of HRPA and absence of eye movements, and parameters changed in concert on either side of the ' $1 F$-state' as expected. However, frequent GM bursts disrupted this state's stability, and led to lack of synchronized transitions (Figure 2). The building up and maintenance of REM sleep and awake states were not influenced by SSRIs.

Clinical characteristics and depression scores of women were similar between the unmedicated and medicated groups. Other factors, including SSRI type, also did not essentially confound alterations in fetal performance. The observed fetal effects may be because of the shared mechanism of action of SSRIs (raising of CNS serotonin), but not to chemical variations among different SSRI types. Our findings in fetuses of medicated women were not explained by factors other than SSRI dosage. The SSRIinduced effect on fetal non-REM sleep seems to be specific, as it has not been described with other fetal exposures (Mulder et al, 1998, 2009, 2010; Van den Bergh et al, 2005). Our unprecedented results show an in utero effect of SSRIs on fetal functioning and challenge the view that adaptation problems in the neonate are solely because of acute cessation of SSRI exposure at birth (withdrawal). The findings also do not lend support to the hypothesis of in utero overstimulation of the serotonergic system or SSRIinduced intoxication (Laine et al, 2003).

Serotonergic neurons in the raphe nuclei project extensively to other brain nuclei that regulate motor activity and sleep-wake cycling ( $\mathrm{Lu}$ et al, 2006; Fuller et al, 2007). The serotonergic system also interacts with other neurotransmitter systems that regulate autonomic control (Bairy et al, 2007), and has an important role in the functional organization of developing neural networks in the brain and spinal cord (Branchereau et al, 2002). Both serotonin neurons and receptors undergo quantitative ontogenetic changes. Therefore, modulation of fetal serotonin by SSRI exposure at different stages of pregnancy may affect structural and functional processes, leading to varied behavioral effects.

Increased activity in SSRI-exposed fetuses supports the view that serotonergic neurons can increase motor output and facilitate execution of repetitive movements in particular (Lucki, 1998; Branchereau et al, 2002). Ontogenetic changes in fetal neurobehavior in the medicated group may also underlie dysregulation of motor control during both non-REM sleep at term and its precursor 'state' at T2 (episode of HRPA). It is puzzling why general movements occur frequently in non-REM sleep and withdraw selectively from inhibitory control after prolonged SSRI exposure. This phenomenon resembles adult sleepwalking occasionally described with the use of SSRIs (Healy et al, 2006). Fetal behavior studies are labor intensive and time consuming. However, fetal observations like ours are of importance for studying the young nervous system and for revealing basic and pathophysiological mechanisms underlying sleep-wake ontogeny and organization (Lu et al, 2006; Fuller et al, 2007).

Neonatal problems often seen after prenatal exposure to SSRIs are time limited and usually resolve within a couple of weeks (Sanz et al, 2005), although exposed infants appear to have increased health utilization during the first year of life (Ververs et al, 2009). Follow-up studies up to 5 years of age are presently reassuring as to the safety of SSRIs. Apart from subtle motor deficits in prenatally exposed infants (Casper et al, 2003), no major effects have been found on cognition, temperament, or internalizing and externalizing behaviors (Nulman et al, 2002; Misri et al, 2006; Oberlander et al, 2007).

From a neurodevelopmental view, however, the signs of non-REM sleep disruption may pose the SSRI-exposed fetus to future risks. In rodents, long-term neurobehavioral effects have been described after perinatal exposure to some individual SSRIs. Noorlander et al (2008) demonstrated in mice that pups exposed to maternally administered daily injections of fluoxetine (but not fluvoxamine) from embryonic days 8-18 exhibit increased anxiety and depression-like behaviors in adulthood (3 months). Similar deficits in adult behavior were found after daily administration of fluoxetine or citalopram over postnatal days (PNDs) 4-21 and PNDs 5-19, respectively (Ansorge et al, 2008; Popa et al, 2008). An early postnatal regimen using citalopram (PNDs 5-19) also resulted in increased total REM sleep (more episodes and shorter latency to sleep onset) in adult mice with no effect on non-REM sleep (Popa et al, 2008), and resulted in reduced sexual activity in male adult rats treated as pups at PNDs 8-21 (Maciag et al, 2006). 
These alterations have been found to be developmentally specific, as they cannot be produced by SSRI treatment at adult age (Ansorge et al, 2008; Popa et al, 2008).

The present study has a number of strengths, including its prospective design, the relatively large sample of human fetuses exposed to SSRIs, and blinded assessments with the use of standardized and comprehensive measures of fetal sleep. In addition, we controlled for multiple potential confounding factors.

Several limitations must be considered. Although the study was longitudinal in character, $45 \%$ of participants in the study groups as opposed to $86 \%$ in the control group did not attend all three antenatal sessions for reasons outlined in the Results section. Therefore, developmental trajectories for individual fetuses could not be assessed with the use of longitudinal data analysis.

There was a difference in parity between the studied groups. However, parity was used as a confounder in the analyses and had no effect on the measures of fetal behavior.

The unmedicated group comprised both women who discontinued taking SSRIs before conception $(n=22)$ and women who were using these drugs at the outset of pregnancy but stopped at first notion of pregnancy $(<8$ weeks; $n=11)$ or stopped at 8-12 wGA $(n=4)$. In the latter subgroups, a potential effect of early SSRI exposure on the developing nervous system cannot be excluded. However, the behavior measures obtained at T1 (18 wGA) and on subsequent occasions did not differ statistically between fetuses exposed for some time during embryogenesis and fetuses of discontinuers before conception. Note that the term 'unmedicated' refers to maternal drug status at first fetal observation (T1).

Another limitation of the study is that its findings cannot be compared with fetal sleep study data from animal experiments on the same subject, as these are not available.

The programming hypothesis suggests that altering key developmental processes in utero can predispose the offspring to late-onset disorders (Gluckman et al, 2008). There is some evidence that poor sleep in children may have prenatal origins (Pesonen et al, 2009). Our results may predict sleep problems in children prenatally exposed to SSRIs. Child sleep problems, in turn, are linked to later behavioral difficulties, anxiety, depression, poor attention, and aggression (Gregory et al, 2008; Pesonen et al, 2009). Hence, future follow-up studies should focus on sleep development and neurophysiological and neuropsychological tests that challenge autonomic control and regulatory/ inhibition mechanisms in prenatally SSRI-exposed individuals.

Treatment decisions for women with psychiatric problems when pregnant or with intention to be are difficult because of conflicting risks (Hampton, 2006). The present study provides data showing that fetal performance varies as a function of different SSRI dosages, not drug type. To stay free of drugs appears to be the optimal choice with respect to potential fetal and obstetrical complications, but relapse of mental disorders is imminent (Cohen et al, 2006). For women who continue SSRI medications in pregnancy, the use of above-standard dosage for a particular SSRI type may be discouraged, if possible and safe.

\section{ACKNOWLEDGEMENTS}

A financial contribution in laboratory costs by The Netherlands Brain Foundation is gratefully acknowledged. We thank the participants of the ongoing Study of Antidepressants in Pregnancy (OAZE) project for their cooperation. We thank gratefully Judie Hulsbosch and Hetty Rijksen for help with patient recruitment and data management, and Mieke Helman for assistance during recording sessions.

\section{DISCLOSURE}

The authors declare no conflict of interest.

\section{REFERENCES}

Andrade SE, Raebel MA, Brown J, Lane K, Livingstone J, Boudreau D et al (2008). Use of antidepressant medications during pregnancy: a multisite study. Am J Obstet Gynecol 198: 194e1-194e 5.

Ansorge MS, Morelli E, Gingrich JA (2008). Inhibition of serotonin but not norepinephrine transport during development produces delayed, persistent perturbations of emotional behavior in adult mice. J Neurosci 28: 199-207.

Bairy KL, Madhyastha S, Ashok KP, Bairy I, Malini S (2007). Developmental and behavioral consequences of prenatal fluoxetine. Pharmacology 79: 1-11.

Branchereau P, Chapron J, Meyrand P (2002). Descending 5-hydroxytryptamine raphe inputs repress the expression of serotonergic neurons and slow the maturation of inhibitory systems in mouse embryonic spinal cord. J Neurosci 22: 2598-2606.

Casper RC, Fleisher BE, Lee-Ancajas JC, Gilles A, Gaylor E, DeBattista A et al (2003). Follow-up of children of depressed mothers exposed or not exposed to antidepressants during pregnancy. J Pediatr 142: 402-408.

Chambers CD, Hernandez-Diaz S, Van Marter L, Werler MM, Louik C, Lyons Jones K et al (2006). Selective serotonin-reuptake inhibitors and risk of persistent pulmonary hypertension of the newborn. $N$ Engl J Med 354: 579-587.

Cohen LS, Altshuler LL, Harlow BL, Nonacs R, Newport DJ, Viguera AC et al (2006). Relapse of major depression during pregnancy in women who maintain or discontinue antidepressant treatment. JAMA 295: 499-507.

Cox JL, Chapman G, Murray D, Jones P (1996). Validation of the Edinburgh Postnatal Depression Scale (EPDS) in non-postnatal women. J Affect Disord 39: 185-189.

Fuller PM, Saper CB, Lu J (2007). The pontine REM switch: past and present. $J$ Physiol 584: 735-741.

Gluckman PD, Hanson MA, Cooper C, Thornburg KL (2008). Effect of in utero and early-life conditions on adult health and disease. $N$ Engl J Med 359: 61-73.

Gregory AM, van der Ende J, Willis TA, Verhulst FC (2008). Parent-reported sleep problems during development and selfreported anxiety, depression, attention problems, and aggressive behaviour later in life. Arch Pediatr Adolesc Med 162: 330-335.

Hampton T (2006). Antidepressants and pregnancy: weighing risks and benefits no easy task. JAMA 295: 1631-1633.

Healy D, Herxheimer A, Menkes DB (2006). Antidepressants and violence: problems at the interface of medicine and law. PLoS Med 3: e372.

Huizink AC, Robles de Medina PG, Mulder EJH, Visser GHA, Buitelaar JK (2002). Psychological measures of prenatal stress as predictors of infant development. J Am Acad Child Adolesc Psych 41: 1078-1085. 
Huizink AC, Mulder EJH, Robles de Medina PG, Visser GHA, Buitelaar JK (2004). Is pregnancy anxiety a distinctive syndrome? Early Hum Dev 79: 81-91.

Kinney HC, Belliveau RA, Trachtenberg FL, Rava LA, Paterson DS (2007). The development of the medullary serotonergic system in early human life. Auton Neurosci 132: 81-102.

Laine K, Heikkinen T, Ekblad U, Kero P (2003). Effects of exposure to selective serotonin reuptake inhibitors during pregnancy on serotonergic symptoms in newborns and cord blood monoamine and prolactin concentrations. Arch Gen Psychiatry 60: 720-726.

Lattimore KA, Donn SM, Kaciroti N, Kemper AR, Neal CR, Vazquez DM (2005). Selective serotonin reuptake inhibitor (SSRI) use during pregnancy and effects on the fetus and newborn: a meta-analysis. J Perinatol 25: 595-604.

Lo WY, Friedman JM (2002). Teratogenicity of recently introduced medications in human pregnancy. Obstet Gynecol 100: 465-473.

Louik C, Lin AE, Werler MM, Hernandez-Diaz S, Mitchell AA (2007). First-trimester use of selective serotonin-reuptake inhibitors and the risk of birth defects. $N$ Engl J Med 356: 2675-2683.

Lu J, Sherman D, Devor M, Saper CB (2006). A putative flip-flop switch for control of REM sleep. Nature 44: 589-594.

Lucki I (1998). The spectrum of behaviors influenced by serotonin. Biol Psychiat 44: 151-162.

Maciag D, Simpson K, Coppinger D, Lu Y, Wang Y, Lin RCS et al (2006). Neonatal antidepressant exposure has lasting effects on behavior and serotonin circuitry. Neuropsychopharmacology 31: 47-57.

Misri S, Reebye P, Kendrick K, Carter D, Ryan D, Grunau R et al (2006). Internalizing behaviors in 4-year-old children exposed in utero to psychotropic medications. Am J Psychiatry 163: $1026-1032$.

Morrison JL, Riggs KW, Rurak D (2005). Fluoxetine during pregnancy: impact on fetal development. Reprod Fertil Dev 17: $1-10$.

Mulder EJH, Visser GHA, Bekedam DJ, Prechtl HFR (1987). Emergence of behavioural states in fetuses of type-1 diabetic women. Early Hum Dev 15: 231-252.

Mulder EJH, Morssink LP, van der Schee T, Visser GHA (1998). Acute maternal alcohol consumption disrupts behavioral state organization in the near-term fetus. Pediatr Res 44: 774-779.

Mulder EJH, de Heus R, Visser GHA (2009). Antenatal corticosteroid therapy: short-term effects on fetal behaviour and haemodynamics. Semin Fetal Neonatal Med 14: 151-156.

Mulder EJH, Tegaldo L, Bruschettini P, Visser GHA (2010). Foetal response to maternal coffee intake: role of habitual versus non-habitual caffeine consumption. J Psychopharmacol 24: 1641-1648.

Nijhuis IJM, ten Hof J, Mulder EJH, Nijhuis JG, Narayan H, Taylor D et al (1998a). Numerical fetal heart rate analysis: nomograms, minimal duration of recording and intrafetal consistency. Prenat Neonat Med 3: 314-322.

Nijhuis IJM, ten Hof J, Mulder EJH, Nijhuis JG, Narayan H, Taylor D et al (1998b). Fetal heart rate (FHR) parameters during FHR patterns A and B: a longitudinal study from 24 weeks' gestation onward. Prenat Neonat Med 3: 383-393.

Nijhuis IJM, ten Hof J, Nijhuis JG, Mulder EJH, Narayan H, Taylor DJ et al (1999). Temporal organization of fetal behavior from 24-weeks gestation onwards in normal and complicated pregnancies. Dev Psychobiol 34: 257-268.

Nijhuis JG, Prechtl HFR, Martin CB, Bots RSGM (1982). Are there behavioural states in the human fetus? Early Hum Dev 6: 177-195.
Noorlander CW, Ververs FFT, Nikkels PGJ, van Echteld CJA, Visser GHA, Smidt MP (2008). Modulation of serotonin transporter function during fetal development causes dilated heart, cardiomyopathy and lifelong behavioral abnormalities. PLoS One 3: e2782.

Nulman I, Rovet J, Stewart DE, Wolpin J, Pace-Asciak P, Shuhaiber $S$ et al (2002). Child development following exposure to tricyclic antidepressants or fluoxetine throughout fetal life: a prospective, controlled study. Am J Psychiat 159: 1889-1895.

Oberlander TF, Reebye P, Misri S, Papsdorf M, Kim J, Eckstein GR (2007). Externalizing and attentional behaviors in children of depressed mothers treated with a selective serotonin reuptake inhibitor antidepressant during pregnancy. Arch Pediatr Adolesc Med 161: 22-29.

Pesonen A-K, Räikkönen K, Matthews K, Heinonen K, Paavonen JE, Lahti J et al (2009). Prenatal origins of poor sleep in children. Sleep 32: 1086-1092.

Popa D, Léna C, Alexandre C, Adrien J (2008). Lasting syndrome of depression produced by reduction in serotonin uptake during postnatal development: evidence from sleep, stress, and behavior. J Neurosci 28: 3546-3554.

Rahimi R, Nikfar S, Abdollahi M (2006). Pregnancy outcomes following exposure to serotonin reuptake inhibitors: a metaanalysis of clinical trials. Reprod Toxicol 22: 571-575.

Sanz EJ, De-las-Cuevas C, Kiuru A, Bate A, Edwards R (2005). Selective serotonin reuptake inhibitors in pregnant women and neonatal withdrawal syndrome: a database analysis. Lancet 365 : 482-487.

Spielberger CD, Gorsuch I, Lushene RE (1970). Manual for the State-Trait Anxiety Inventory. Consulting Psychologists Press: Palo Alto, CA.

ten Hof J, Nijhuis IJM, Mulder EJH, Nijhuis JG, Narayan H, Taylor $\mathrm{D}$ et al (2002). Longitudinal study of fetal body movements: nomograms, intrafetal consistency, and relationship with episodes of heart rate patterns A and B. Pediatr Res 52: 568-575. ten Hof J, Nijhuis IJM, Nijhuis JG, Narayan H, Taylor D, Visser GHA et al (1999). Quantitative analysis of fetal general movements: methodological considerations. Early Hum Dev 56: 57-73.

Van den Bergh BRH, Mulder EJH, Mennes M, Glover V (2005). Antenatal maternal anxiety and stress and the neurobehavioral development of the fetus and child: links and possible mechanisms. A review. Neurosci Biobehav Rev 29: 237-258.

Vaswani M, Linda FK, Ramesh S (2003). Role of selective serotonin reuptake inhibitors in psychiatric disorders: a comprehensive review. Prog Neuropsychopharmacol Biol Psychiatry 27: 85-102.

Ververs FFT, Kaasenbrood H, Visser GHA, Schobben F, de Jongvan den Berg L, Egberts T (2006). Prevalence and patterns of antidepressant drug use during pregnancy. Eur J Clin Pharmacol 62: $863-870$.

Ververs FFT, van Wensen K, Freund MW, van der Heide M, Visser GHA, Schobben AF et al (2009). Association between antidepressant drug use during pregnancy and child health care utilisation. BJOG 116: 1568-1577.

Visser GHA, Mulder EJH, Prechtl HFR (1992). Studies on developmental neurology in the human fetus. Dev Pharmacol Ther 18: 175-183.

Visser GHA, Eilers PHC, Elferink-Stinkens PM, Merkus HMWM, Wit JM (2009). New Dutch reference curves for birthweight by gestational age. Early Hum Dev 85: 737-744.

WHO Collaborating Centre for Drug Statistics (2008). ATC/DDD index 2008. Oslo, Norway. Available at www.whocc.no.

Zeskind PS, Stephens LE (2004). Maternal selective serotonin reuptake inhibitor use during pregnancy and newborn neurobehavior. Pediatrics 113: 368-375. 